\title{
Modelling the impact of climate variability and irrigation on winter canola yield and yield gap in Southwest China
}

\author{
$\underline{\text { Di He }}^{\text {a,b }}$, Jing Wang a and Enli Wang ${ }^{b}$ \\ ${ }^{a}$ College of Resources and Environmental Sciences, China Agricultural University, Beijing 100193, China \\ ${ }^{b}$ CSIRO Agriculture, GPO Box 1666, Black Mountain, Canberra ACT 2601, ACT, Australia \\ Email:Di.He@,csiro.au
}

\begin{abstract}
Southwest China (SWC) is one of the major canola production areas in China. Due to frequent seasonal drought during the canola growing season, irrigation plays a vital role in improving canola yields. However, the impact of irrigation and climate variations on canola yield and the yield gap (the difference between potential and rainfed yield) has not been properly addressed. Existing experimental data are limited and are not sufficient to answer these questions. A modelling study is therefore warranted to extend the experimental findings.
\end{abstract}

In this study, we used a modeling approach to quantify the yield potential and the yield gap of canola crop, how they are affected by inter-annual climate variability, and how much water is required for irrigation to close the yield gap in southwest China. The APSIM-Canola model was firstly calibrated and validated against experimental data at Yuxi site in SWC from 1981 to 1989. The model was then used to simulate the canola yield under irrigation and rainfed conditions from 1961 to 2010. The simulation results were used to explore the impact of different irrigation scenarios on canola yield.

From 1961 to 2010 , minimum temperature increased by $0.5^{\circ} \mathrm{C}$ per decade $(p<0.01)$ during the canola growing season, whereas daily global radiation decreased by $0.3 \mathrm{MJ} \mathrm{m}^{-2}$ per decade $(p<0.01)$. Growing season precipitation ranged from 44.3 to $310.9 \mathrm{~mm}$ with a non-significant decreasing trend. The warming and dimming trend from 1961 to 2010 was estimated to reduce the potential yield at the rate of $151 \mathrm{~kg} \mathrm{ha}^{-1}$ per decade $(p<$ 0.01 ), mainly due to reduced radiation and length of growing period.

Simulation results with a single hybrid cultivar showed that the potential canola yield under fully irrigation $\left(3452 \mathrm{~kg} \mathrm{ha}^{-1}\right)$ is about three times the rainfed yield $\left(1215 \mathrm{~kg} \mathrm{ha}^{-1}\right)$. Improved irrigation increases yield and water productivity, particularly in dry seasons. To achieve $\sim 80 \%$ of the potential yield, an average amount of $330.1 \mathrm{~mm}, 302.9 \mathrm{~mm}$, and $265.2 \mathrm{~mm}$ irrigation water, were required for canola in wet, medium, and dry seasons, respectively. Longer season canola cultivars may help to mitigate the negative impact of further climate warming in the future.

Keywords: Potential yield, rainfed potential, crop water productivity, water management, APSIM-Canola 


\section{INTRODUCTION}

Canola (Brassica napus L.) is the main winter-growing oilseed crop in China with an annual harvested area of $7.50 \mathrm{M}$ ha and average farm yield of $1900 \mathrm{~kg} \mathrm{ha}^{-1}$ in 2013. From 1961 to 2013, the average annual production in China was 6.20 M t, which accounts for $\sim 20 \%$ of the world total (Faostat, 2013). Southwest China (SWC), as a part of Yangtze River Basin, is one of the major canola production areas of China (Wang et al., 2012b), where the dominant cropping system is a canola-rice double rotation. The canola crop is normally sown in the autumn and harvested in early summer. From 2005 to 2010, the average annual harvested area in SWC was $2.03 \mathrm{M}$ ha, accounting for about one third of the national oilseed area of China. In spite of the importance of SWC for canola production, the canola yield is not stable, but varies significantly from year to year due to variability of seasonal rainfall.

One of the key factors affecting canola yield in SWC is the frequent seasonal drought from autumn to the next spring (Wang et al., 2012a). Statistics shows that from 1959 to 2008 the drought frequency was more than 50\% in Sichuan and Yunnan provinces in SWC, i.e. draught occurring in more than half of the years (Yang and $\mathrm{Li}$, 2014). In order to stabilize and increase canola yield, irrigation is being considered. However, there is a lack of studies to quantify the yield potential and the yield gap for canola crop, how they are affected by inter-annual climate variability, and how much water is required for irrigation to close the yield gap. Existing experimental data are limited and are not sufficient to answer these questions. A modelling study is therefore warranted to extend the experimental findings.

The Agricultural Production Systems Simulator, APSIM (Holzworth et al., 2015), has been successfully applied in China to study the impacts of climate variability on crop production (Liu et al., 2012; Wang et al., 2014), field water balance (Wang et al., 2008 ), and crop yield response to irrigation management (Chen et al., 2010). The model has also been used to investigate impact of sowing time and $\mathrm{N}$ application on canola yield in the Yangtze River Basin (Wang et al., 2012).

The objectives of this study are to: (i) quantify the potential yield, rainfed yield, and the yield gap of canola crop in SWC and how they respond to historical climate variability, (ii) investigate the potential impact of different irrigation scenarios on canola yield and water productivity, and (iii) explore optimal irrigation strategies for canola in different rainfall season types.

\section{MATERIALS AND METHODS}

\subsection{Study site, climate, and crop data}

The study site is Yuxi $\left(24.3^{\circ} \mathrm{N}, 102.6^{\circ} \mathrm{E}, 1716.9 \mathrm{~m}\right)$, located in Yunnan Province in SWC, representative of the climate and soil conditions of the SWC canola production area. The site is characterised by subtropical humid monsoon climate. The annual average temperature and total precipitation (1960-2010) during the canola season are $13.2^{\circ} \mathrm{C}$ and $184.6 \mathrm{~mm}$, respectively. The soil is a paddy soil and the soil profile properties are shown

Table 1. Soil properties at the study site Yuxi

\begin{tabular}{cccccc}
\hline $\begin{array}{c}\text { Soil depth } \\
(\mathrm{cm})\end{array}$ & $\begin{array}{c}\text { BD } \\
\left(\mathrm{g} / \mathrm{cm}^{-3}\right)\end{array}$ & $\begin{array}{c}\mathrm{LL} \\
(\mathrm{mm} / \mathrm{mm})\end{array}$ & $\begin{array}{c}\text { DUL } \\
(\mathrm{mm} / \mathrm{mm})\end{array}$ & $\begin{array}{c}\text { SAT } \\
(\mathrm{mm} / \mathrm{mm})\end{array}$ & $\begin{array}{c}\mathrm{pH} \\
(-)\end{array}$ \\
\hline $0-19$ & 1.26 & 0.24 & 0.39 & 0.53 & 7.0 \\
$19-25$ & 1.32 & 0.23 & 0.38 & 0.50 & 7.2 \\
$25-59$ & 1.39 & 0.22 & 0.37 & 0.48 & 7.2 \\
$59-70$ & 1.28 & 0.29 & 0.42 & 0.52 & 7.2 \\
$70-100$ & 1.28 & 0.29 & 0.42 & 0.52 & 7.2 \\
\hline
\end{tabular}

BD: bulky density; LL: lower limit; DUL: field capacity; SAT: saturation in Table 1.

An agro-meteorological station was located at the study site. It belongs to the China Meteorological Administration. The station has a crop field to observe crop growth and yield, and a standard meteorological station to record daily weather data including maximum, minimum temperature, rainfall, and sunshine hours. The canola cultivar Shengli was grown from 1985 to 1989 . The observed crop data includes key phenological stages (sowing, emergence, flowering, and maturity date), plant density, final biomass, and yield. Fertilizer and irrigation applications were recorded. Historical daily weather data (1961 to 2010) was obtained from the China Meteorological Administration for the Yuxi site. Sunshine hours were converted into daily global radiation using the Angstrom equation (Black et al., 1954).

\subsection{The APSIM-Canola model}

APSIM version 7.6 was used in this study. The canola module in APSIM was developed in the late 1990s (Robertson et al., 1999), which simulates canola development, growth, yield, and nitrogen accumulation in response to temperature, photoperiod, soil water, and nitrogen supply with a daily time-step. 
APSIM-Canola has been tested for many spring type cultivars across a range of environments in Australia (Robertson et al., 1999), but less for winter type cultivars (Lilley et al., 2015). The first canola modeling study using APSIM-Canola in China was done by Wang et al. (2012), who tested the model in the Yangtze River Basin, and found that the model captured the observed biomass dynamics and grain yield of canola in response to different sowing dates. Impact of irrigation on canola yield was not investigated in the previous study.

\subsection{Derivation of cultivar parameters}

Culitvar parameters in APSIM-Canola mainly include the thermal time targets for the key phenological phases and response of crop development to vernalisation and photoperiod (Table 2). These parameters were derived using the optimization process described in Robertson et al. (2002) and Lilley et al. (2015). Briefly, a value range was assumed for each of the parameters based on prior knowledge, and the Nelder-Mead optimization method in R was used to minimize the root mean square error (RMSE) and normalized root mean square error (NRMSE) between the observed and simulated durations of emergence to flowering and flowering to maturity:

$$
\begin{aligned}
R M S E & =\sqrt[2]{\sum_{i=1}^{n}\left(S_{i}-O_{i}\right)^{2} / n} \\
N R M S E & =\sqrt[2]{\sum_{i=1}^{n}\left(S_{i}-O_{i}\right)^{2} / n} / \bar{O}
\end{aligned}
$$

where $\mathrm{O}_{\mathrm{i}}$ and $\mathrm{S}_{\mathrm{i}}$ are the paired observed and simulated durations, $\bar{O}$ is the average of the observed duration, and $\mathrm{n}$ is the number of observations.

The derived parameters were needed to correctly simulate the phenology of the canola cultivar Shengli. We tested the model for its ability to simulate the total biomass. The harvest index was also derived using the optimization process in order to correctly simulate grain yield. Apart from these cultivar parameters, no other parameters in the model were modified.

\subsection{Yield gap and irrigation scenarios}

In this study, the potential yield was defined as the maximum yield achieved with no water and nutrient stress. The rainfed yield was the yield achieved with no nutrient stress, under rainfed conditions (no irrigation). The yield gap was the difference between the potential yield and rainfed yield due to water stress.

Flowering and grain filling stages are the critical water requirement stages of canola. Thus, one (at start of flowering stage), two (at start and full flowering stages), three (at start flowering, full flowering, and grain filling stages), and four (at start flowering, full flowering, grain filling, and green ripe stages) times of irrigation applications were simulated. In each scenario, irrigation was applied based on the soil water content, with the amount of water to fill the soil $(0-100 \mathrm{~cm})$ to field capacity. Crop water productivity was calculated as grain yield divided by evapotranspiration during the growing season.

We separated three different season types using the mean and standard deviation (SE) of growing season rainfall from 1961 to 2010: dry seasons - rainfall lower than the mean minus one $\mathrm{SE}$ $(150.8 \mathrm{~mm})$, wet seasons rainfall higher than the mean plus one SE (287.4 mm), and medium seasons - the remaining seasons.

\begin{tabular}{|c|c|c|c|c|}
\hline APSIM parameter & Explanation & Unit & default & Shengli \\
\hline cumvd_emergence & Required vernalisation days & day & 50 & 50 \\
\hline pp_end_of_juvenile & & $\mathrm{h}$ & $10.8,16.3$ & $10.8,16.3$ \\
\hline tt_end_of_juvenile & Photoperiod thresholds & ${ }^{\circ} \mathrm{C} \mathrm{d}$ & 900,430 & 400,330 \\
\hline hi_max_pot & Harvest index & - & 0.3 & 0.16 \\
\hline & Thermal time requirements: & & & \\
\hline tt_emergence & Emergence to end of juvenile & ${ }^{\circ} \mathrm{C} \mathrm{d}$ & 500 & 650 \\
\hline tt_floral_initiation & Floral initiation to flowering & ${ }^{\circ} \mathrm{C} \mathrm{d}$ & 250 & 160 \\
\hline tt_flowēing & Flowering to start grain filling & ${ }^{\circ} \mathrm{C} \mathrm{d}$ & 200 & 175 \\
\hline tt_start_grain_fill & $\begin{array}{l}\text { Start grain filling to end grain } \\
\text { filling }\end{array}$ & ${ }^{\circ} \mathrm{C} \mathrm{d}$ & 1000 & 800 \\
\hline
\end{tabular}

Table 2. Cultivar parameters for APSIM_canola at Yuxi (Cultivar: Shengli)

\section{RESULTS AND DISCUSSIONS}

\subsection{APSIM performance}

Table 2 shows the derived parameter for canola cultivar Shengli, and Table 3 shows the performance of the model after calibration. Observed days from sowing to flowering and sowing to maturity ranged from 99 to $106 \mathrm{~d}$ and from 169 to $190 \mathrm{~d}$, respectively. The derived cultivar parameters lead to a RMSE for flowering and maturity time of 2.2 and 4.5 days, which was $2.3 \%$ and $5.6 \%$ of the mean period from emergence to flowering 
Table 3. Observed versus simulated flowering and maturity dates (days after sowing), grain yield, and biomass. (O represents observed value, and $\mathrm{S}$ represents simulated value)

\begin{tabular}{ccccccccc}
\hline Year & \multicolumn{2}{c}{$\begin{array}{c}\text { DEF } \\
(\mathrm{d})\end{array}$} & \multicolumn{2}{c}{$\begin{array}{c}\text { DFM } \\
(\mathrm{d})\end{array}$} & \multicolumn{2}{c}{$\begin{array}{c}\text { Grain yield } \\
\left(\mathrm{kg} \mathrm{ha}^{-1}\right)\end{array}$} & \multicolumn{2}{c}{$\begin{array}{c}\text { Biomass } \\
\left(\mathrm{kg} \mathrm{ha}^{-1}\right)\end{array}$} \\
\cline { 2 - 10 } & $\mathrm{O}$ & $\mathrm{S}$ & $\mathrm{O}$ & $\mathrm{S}$ & $\mathrm{O}$ & $\mathrm{S}$ & $\mathrm{O}$ & $\mathrm{S}$ \\
\cline { 2 - 10 } 1986 & 100 & 101 & 86 & 86 & 2813 & 2916 & 21305 & 18356 \\
1987 & 94 & 97 & 71 & 79 & 2250 & 2307 & 14249 & 14469 \\
1988 & 97 & 96 & 86 & 82 & 2962 & 2558 & 13352 & 16040 \\
1989 & 102 & 99 & 79 & 80 & 2775 & 2795 & 17437 & 17561 \\
\hline RMSE & \multicolumn{2}{c}{2.2} & \multicolumn{2}{c}{4.5} & \multicolumn{2}{c}{210} & \multicolumn{1}{c}{1999} \\
NRMSE & $2.3 \%$ & \multicolumn{2}{c}{$5.6 \%$} & \multicolumn{2}{c}{$7.9 \%$} & \multicolumn{1}{c}{$11.9 \%$} \\
\hline
\end{tabular}

DEF: days from emergence to flowering; DFM: days from flowering to maturity and from flowering to maturity, respectively. Measured biomass ranged from $13,352 \mathrm{~kg} \mathrm{ha}^{-1}$ to $21,305 \mathrm{~kg} \mathrm{ha}^{-1}$. The RMSE for biomass simulation was $1999 \mathrm{~kg} \mathrm{ha}^{-1}$ that was $11.9 \%$ of the observed average biomass. The observed grain yield ranged from $2250 \mathrm{~kg} \mathrm{ha}^{-1}$ to $2977 \mathrm{~kg} \mathrm{ha}^{-}$

1 . Grain yield simulations

had a RMSE of $210 \mathrm{~kg} \mathrm{ha}^{-1}$ and NRMSE of $7.9 \%$, respectively. The performance of the model is therefore considered to be satisfactory for the simulation of canola phenology, biomass, and yield.

\subsection{Trends and variations in climate variables}

Trends and variations in climate variables during canola growing season from 1960 to 2010 at Yuxi site were shown in Fig. 1. Growing season average minimum and maximum temperatures ranged from 5.3 to $9.0{ }^{\circ} \mathrm{C}$ and from 18.5 to $21.6^{\circ} \mathrm{C}$, respectively, with the average value of 6.7 and $19.8{ }^{\circ} \mathrm{C}$ and a standard deviation of 1.0 and 0.7 ${ }^{\circ} \mathrm{C}$, respectively. While no significant changes in average maximum temperature was detected (Fig 1a), average minimum temperature had a significant increasing trend of $0.5^{\circ} \mathrm{C}$ per decade $(p<0.01$, Fig. $1 b)$, mainly caused by increase since early 1990s. Daily average global radiation during canola growing season varied between 13.21 and $16.80 \mathrm{MJ} \mathrm{m}^{-2} \mathrm{~d}^{-1}$ with standard deviation of $0.88 \mathrm{MJ} \mathrm{m}^{-2}$
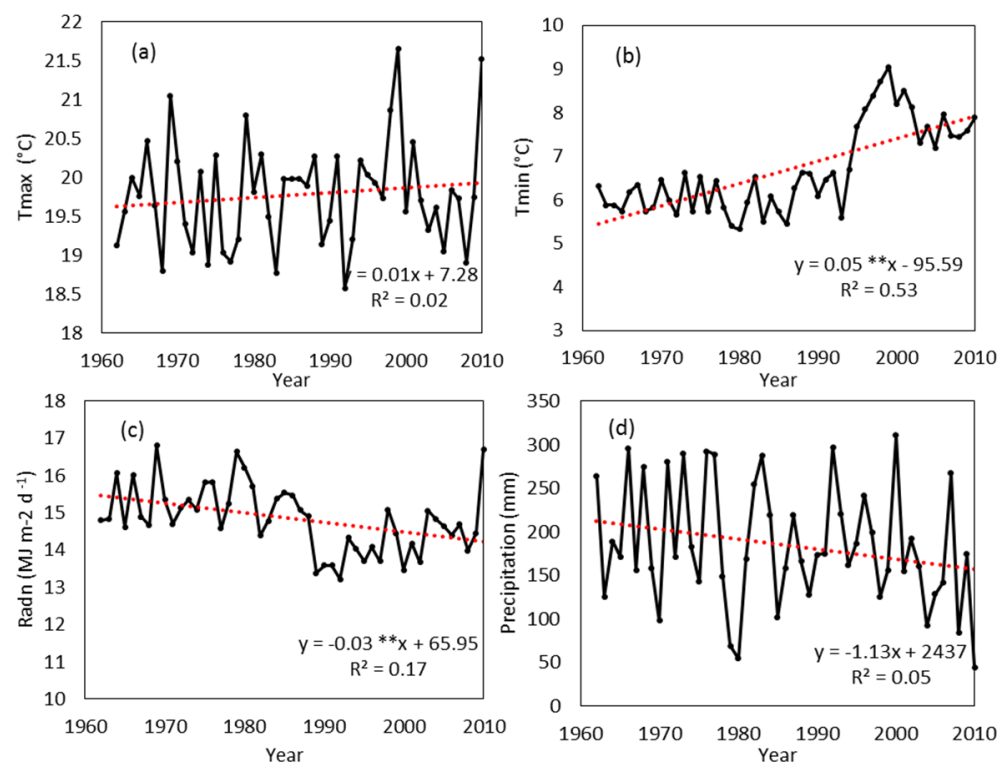

Figure 1. Mean maximum temperature $\left(\mathrm{a},{ }^{\circ} \mathrm{C}\right)$, minimum temperature

$\left(\mathrm{b},{ }^{\circ} \mathrm{C}\right)$, daily average global radiation $\left(\mathrm{c}, \mathrm{MJ} \mathrm{m}^{-2} \mathrm{~d}^{-1}\right)$, and total precipitation $(\mathrm{d}, \mathrm{mm})$ during canola growing season at Yuxi site from

1962 to $2010{ }^{* *}$ indicates statistical significance at $p<0.01$.

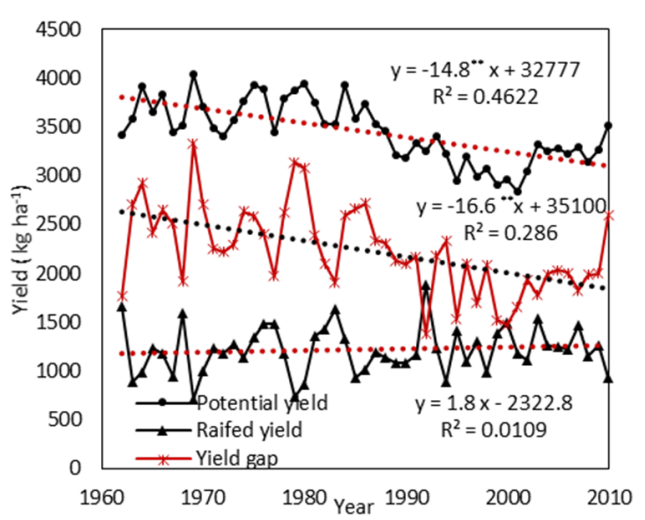

Figure 2. Potential yield, rainfed yield and yield gap of canola simulated by APSIM at Yuxi site from 1962 to 2010. ** indicates statistical significance at $p<0.01$. $\mathrm{d}^{-1}$. It decreased significantly at a rate of $0.3 \mathrm{MJ} \mathrm{m}^{-}$ ${ }^{2} \mathrm{~d}^{-1}$ per decade $(p<0.01$, Fig. 1c). Growing season precipitation ranged from 44.3 to $310.9 \mathrm{~mm}$ with a standard deviation of $70.0 \mathrm{~mm}$ and decreased at a rate of $11.3 \mathrm{~mm}$ per decade ( $p>0.05$, Fig. 1d).

\subsection{Change in canola potential yield, rainfed yield, and yield gap}

Mean potential yield and rainfed yield of canola at Yuxi were 3453 and $1215 \mathrm{~kg} \mathrm{ha}^{-1}$ from 1962 to 2010 , with variation coefficients of $9.0 \%$ and 20.1 $\%$, respectively (Fig. 2). The potential yield ranged from 2839 to $4046 \mathrm{~kg} \mathrm{ha}^{-1}$, showing a declining trend of $150 \mathrm{~kg} \mathrm{ha}^{-1}$ per decade $(p<0.01)$. The rainfed yield showed a slightly increasing trend, but it was not significant. The yield gap between the 
potential yield and rainfed yield, ranged from 1378 to $3336 \mathrm{~kg} \mathrm{ha}^{-1}$. Mean yield gap of canola was $2237 \mathrm{~kg} \mathrm{ha}^{-}$ 1 , accounting for $64.8 \%$ of the potential yield, with coefficient of variation of $19.8 \%$. Yield gaps decreased from 1962 to 2010 at a rate of $166 \mathrm{~kg} \mathrm{ha}^{-1}$ per decade, mainly caused by the decrease of the potential yield ( $p$ $<0.01$ ). To obtain potential yield, the crop would require 625 to $1019 \mathrm{~mm}$ water, implying a water deficit of 469.0 to $777.8 \mathrm{~mm}$ compared to the growing season rainfall (Fig 3). . The large gap between the potential and rainfed yield indicates that water stress was a major factor limiting canola yield in SWC (He et al., 2014). There was a large potential to increase canola yield through better irrigation scheduling and improvement of precipitation use efficiency in SWC.

\subsection{Yield and water productivity under different water management and climate conditions}

Simulated canola yield and irrigation amounts from 1962 to 2010 under different irrigation scenarios are shown in Fig. 3. Canola yields increased significantly when irrigations were applied (Fig. 3). Increasing irrigation amount increased yield and reduced yield variability (Fig. 3). There was only a small increase in yield from one to two irrigations (from 1726 to $\left.1788 \mathrm{~kg} \mathrm{ha}^{-1}\right)$. Irrigation amount under each irrigation scenarios varied greatly due to inter-annual
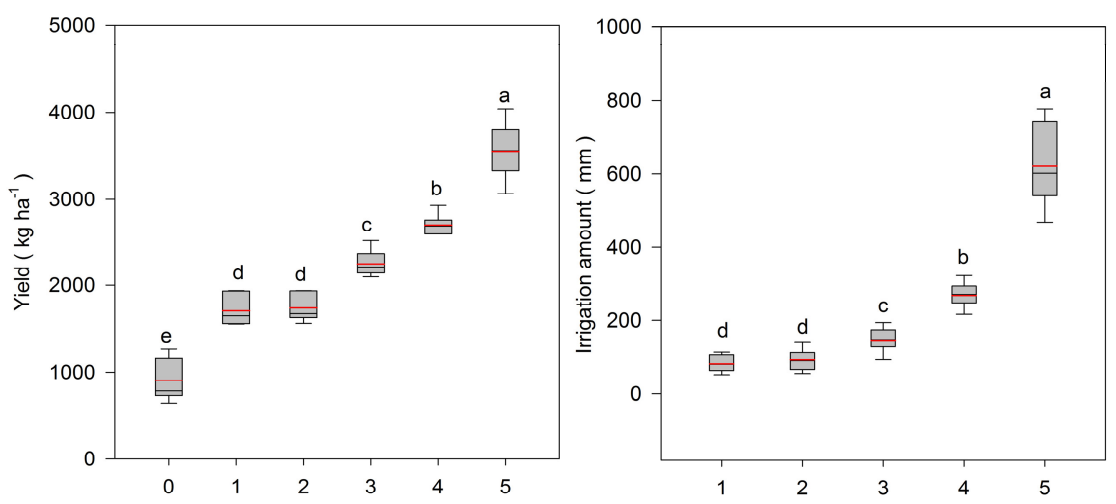

Figure 3. Simulated canola yield and the corresponding irrigation amounts at Yuxi site from 1962 to 2010, and 0, 1, 2, 3, 4 refer to zero-, one-, two-, three-, and four- irrigation treatments, respectively. 5 refers to the potential yield and corresponding water deficit comparing to growing season rainfall. The box plots show the $10,25,75$, and 90 percentiles, and the red line represents the average value. Different alphabets indicate significant differences $(p<0.05)$.

rainfall variability. The averaged irrigation amount increased from 82.7 to $267.8 \mathrm{~mm}$ with the increasing number of irrigations (Fig 3). The variation coefficients of the amount of irrigation were large under each treatment, which were $29.9 \%, 32.9 \%, 23.4 \%, 14.6 \%$ for one, two, three, and four irrigations, respectively. The high variations in irrigation amount were mainly caused by different rainfall year types.

Water productivity of canola under each irrigation treatments was shown in Fig. 4. The average water productivity reached the maximum value of $0.51 \mathrm{~kg} \mathrm{~m}^{-3}$ under the three-irrigation treatment with variation coefficient of $7.4 \%$ (Fig. 4). Water productivity under rainfed condition was lowest $\left(0.46 \mathrm{~kg} \mathrm{~m}^{-3}\right)$ with large variation from 0.33 to $0.55 \mathrm{~kg} \mathrm{~m}^{-3}$. Rainfed water productivity was significant different from other irrigation ones $(p<0.05)$, however, there was no significant difference in water productivity between different irrigation treatments $(p>0.05)$

\subsection{Irrigation management under different rainfall season types}

Grain yield, water productivity, irrigation amount, and yield gap between potential yield and irrigated yield in different rainfall years were shown in Fig. 5. Grain yield increased with irrigation in all season types, indicating water stress in almost all years. Water productivity under irrigation across different season types was similar, contrasting to that under rainfed (zero irrigation) $(p>0.05)$. There was no significant irrigation-season type interaction at Yuxi stie. For all the season types, one-irrigation can obtain the highest water

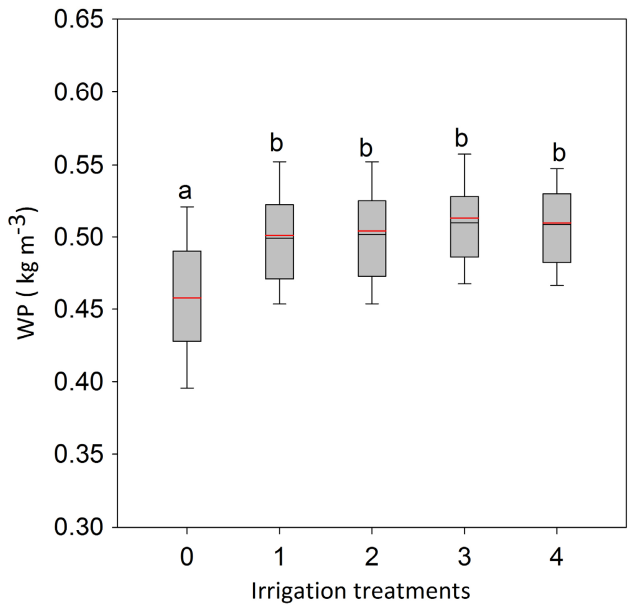

Figure 4. Simulated water productivity as affected by different irrigation scenarios at Yuxi site from 1962 to 2010, and 0, 1, 2, 3, 4 refer to zero-, one-, two-, three-, and four- irrigation treatments, respectively. The box plots show the $10,25,75$, and 90 percentiles, and the red line represents the average value. Different alphabets indicate significant differences $(p<0.05)$. 
productivity, $110.0 \mathrm{~mm}, 84.2 \mathrm{~mm}, 70.9 \mathrm{~mm}$ irrigation amounts were recommended under dry, medium, and wet season types. While in order to obtain $\sim 80 \%$ of the potential yield, four-irrigation were recommended with $330.1 \mathrm{~mm}, 302.9 \mathrm{~mm}$, and $265.2 \mathrm{~mm}$ irrigation amounts for canola under dry, medium, and wet season types, respectively.

\section{CONCLUSION}

This study reveals that in SWC the canola yield potential under full irrigation is about three times of the rainfed yield, indicating a large potential to increase yield through irrigation. The current yield (represented by the yield at experimental station) is only about twice of the rainfed yield, implying that a large yield gap still remains. Improved irrigation management could further increase canola yield. Our results also show that improved irrigation could increase both yield and water productivity, particularly in dry seasons.

Irrigation has been practiced in some places at SWC for canola crop, but is still very limited. At the study site, surface water
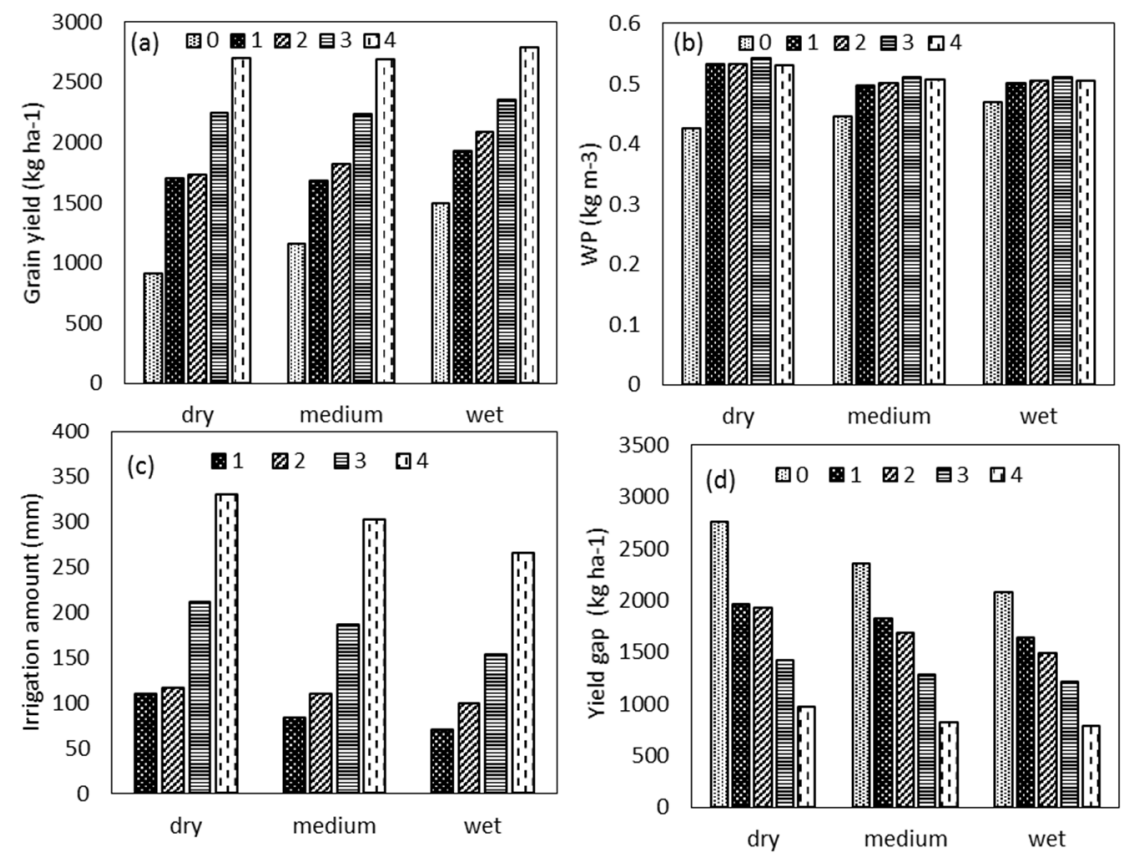

Figure 5. Average of simulated grain yield (a), water productivity (b), irrigation amount (c), and yield gap between potential yield and irrigated yield (d) as affected by different irrigation scenarios at Yuxi site from 1962 to 2010, and 0, 1, 2, 3, 4 refer to zero-, one-, two-, three-, and four- irrigation treatments, respectively.

resources exist due to the high annual rainfall (average of $1049 \mathrm{~mm}$ ), thus irrigation development has the potential to mitigate the impact of seasonal drought during canola season in SWC (He et al., 2014). Rainwater harvesting has been widely applied for crop production in arid and semi-arid region, which is effective in increasing yield and water use efficiency. Collection of rainfall and runoff can also be an effective method to increase canola yield and as an adaptation to climate warming across SWC.

The past warming from 1961-2010 was simulated to reduce the potential yield of canola crop, mainly due to reduced radiation and length of growing period. In order to maintain the yield potential, longer season canola cultivars may be needed to reduce the negative impact of climate warming.

\section{ACKNOWLEDGEMENTS}

This work is supported by the National Basic Research Program of China (2013CB430205), National Agricultural Introducing Intelligence Platform of China (2015z007), and China Scholarship Council. We would like to thank China Meteorological Administration for providing the historical climate data and agrometeorological data.

\section{REFERENCES}

Black, J. N., Bonython, C. W., and Prescott, J. A. (1954). Solar radiation and the duration of sunshine. Quarterly Journal of the Royal Meteorological Society, 80(344), 231-235.

Chen, C., Wang, E., and Yu, Q. (2010). Modelling the effects of climate variability and water management on crop water productivity and water balance in the North China Plain. Agricultural Water Management, 97(8), $1175-1184$. 
Faostat, F. A. O. (2013). Statistical Databases. Food and Agriculture Organization of the United Nations. http://faostat3.fao.org/.

He, D., Wang, J., Dai, T., Feng, L., Zhang, J., Pan, X., Pan, Z. (2014). Impact of climate change on maize potential productivity and the potential productivity gap in southwest China. Journal of Meteorological Research, 28, 1155-1167.

Holzworth, D. P., Snow, V., Janssen, S., Athanasiadis, et al. (2015). Agricultural production systems modelling and software: Current status and future prospects. Environmental Modelling \& Software. doi:10.1016/j.envsoft.2014.12.013

Lilley, J. M., Bell, L. W., and Kirkegaard, J. A. (2015). Optimising grain yield and grazing potential of crops across Australia's high-rainfall zone: a simulation analysis. 2. Canola. Crop and Pasture Science, 66(4), 349-364.

Liu, Z., Yang, X., Hubbard, K. G., and Lin, X. (2012). Maize potential yields and yield gaps in the changing climate of northeast China. Global Change Biology, 18(11), 3441-3454.

Robertson, M. J., Asseng, S., Kirkegaard, J. A., et al. (2002). Environmental and genotypic control of time to flowering in canola and Indian mustard. Crop and Pasture Science, 53(7), 793-809.

Robertson, M. J., Holland, J. F., Kirkegaard, J. A., and Smith, C. J. (1999). Simulating growth and development of canola in Australia. In Proceedings of the 10th International Rapeseed Congress'. Canberra, ACT.

Wang, E., Yu, Q., Wu, D., and Xia, J. (2008). Climate, agricultural production and hydrological balance in the North China Plain. International Journal of Climatology, 28(14), 1959-1970.

Wang, J., Wang, E., Yin, H., Feng, L., and Zhang, J. (2014). Declining yield potential and shrinking yield gaps of maize in the North China Plain. Agricultural and Forest Meteorology, 195, 89-101.

Wang, M., Wang, X., Huang, W., Zhang, Y., and Ma, J. (2012a). Temporal and spatial distribution of seasonal drought in Southwest of China based on relative moisture index. Transactions of the Chinese Society of Agricultural Engineering, 28(19), 85-92. (in Chinese)

Wang, S., Wang, E., Wang, F., and Tang, L. (2012b). Phenological development and grain yield of canola as affected by sowing date and climate variation in the Yangtze River Basin of China. Crop and Pasture Science, 63(5), 478-488.

Yang X. and Li M. (2014) Seasonal Drought in Southern China: Characteristics and Adaptation of Cropping System. China Meteorological Press, Beijing. 